\title{
28. Durch Arthropoden übertragene (Arbor) Viruskrankheiten
}

Die Arborviren (durch Arthropoden übertragene = Arthropod - borne) sind dadurch charakterisiert, daß sie sich in Arthropoden vermehren können, ohne in diesem Wirt offensichtliche Krankheitssymptome oder Gewebsschäden hervorzurufen. Die Übertragung dieser Viren auf den Menschen oder auf andere Säugetiere und Vögel erfolgt durch den Biss des Arthropoden. Dieser als Vektor dienende Arthropode wird wiederum beim Blutsaugen an einem infizierten Wirt, in dessen Blut das Virus zirkuliert, infiziert.

Aborviren sind vor allem in den tropischen Regenwäldern der Erde verbreitet. Diese Verbreitung ist im Hinblick auf die günstigen klimatischen Bedingungen, die Vielzahl der dort lebenden Tiere der verschiedensten Arten und der Insekten verständlich. Da die Arborviren durch einen Lebenszyklus erhalten werden, bei dem sowohl Arthropoden als auch Wirbeltiere beteiligt sind, zeigen die Tropen die günstigsten Bedingungen für die Aufrechterhaltung dieses biologischen Zyklus.

Die Arborvirusgruppe besteht aus zumindest 120 verschiedenen Viren, die gegenwärtig entsprechend ihrer Antigenverwandtschaft in mehrere Untergruppen eingeteilt werden. Jede dieser Gruppen besteht aus verschiedenen Mitgliedern, die in einem unterschiedlichen Ausmaß gemeinsame, durch die Komplementbindungsreaktion (KBR), den Hämagglutinationshemmungstest (HHT) und - weniger häufig - durch den Neutralisationstest nachweisbare Antigene besitzen.

1. Gruppe A: Die Viren der östlichen, westlichen und der Venezuela Pferdeencephalitis sind im hohen Maße pathogen für das Zentralnervensvstem des Kaninchens und des Meerschweinchens und unterscheiden sich dadurch von den neurotropen Viren der Gruppe B der Arborviren. Diese drei Pferdeencephalitisviren unterscheiden sich ebenfalls von den Viren der japanischen B-Encephalitis, der St. Louis Encephalitis, der Murrav Vallev Encephalitis, des West Nile Fieber, der russischen Frïhiahrs-Sommer-Encephalitis und des Louping ill in ihren Wachstumserfordernissen an Mäuse aus genetisch unterschiedlichen Zuchten. Ferner gehört zu dieser Gruppe A das Mayaro Virus (Trinidad, Brasilien, Bolivien), das Semliki Virus (Afrika), das Chikungunya Virus (Afrika, Südost-Asien), das Sindbis Virus (Afrika und Indien), die Aura- und Una Viren (Brasilien), das Uruma Virus (Bolivien), das Middelburg Virus (Südafrika) und O'nyong - nyong Virus (Uganda). Das O'nyong nyong Virus war 1960 die Ursache eines Ausbruchs einer Dengue-ähnlichen Erkrankung in Zentralafrika, bei der etwa 750000 menschliche Erkrankungsfälle auftraten.

2. Gruppe B: Die Viren der japanischen B-Encephalitis, der St. Louis und Murray Valley Encephalitis zeigen eine ausgeprägte Kreuzreaktion miteinander, die sich auch auf das Virus des West Nile Fiebers, des brasilianischen Bussuquara und des Texas-Kalifornischen Speicheldrüsenvirus der Fledermäuse erstreckt. In einem geringeren Ausmaß besteht auch eine Verwandtschaft mit dem Virus des Gelbfiebers und den Dengueviren. Das Virus der russischen Frühjahrs-Sommer-Encephalitis zeigt eine sehr deutliche Kreuzreaktion mit dem Virus der Kyasanur Waldkrankheit, dem Erreger einer schweren und häufig tödlich endenden Erkrankung von Menschen und Affen in Indien, ferner mit dem Virus des 
haemorrhagischen Fiebers von Omsk und dem Louping ill Virus, dem Erreger einer Schafkrankheit in einigen Gegenden Schottlands und im nördlichen England. Das Virus der russischen Frühjahrs-Sommer-Encephalitis zeigt eine weniger ausgeprägte Kreuzreaktion mit den anderen Mitgliedern der Gruppe B, hierzu gehören das Zika, Uganda S, Ntaya und Ilheus Virus. Weitere Mitglieder dieser Gruppe B sind das Modoc, das Spondweni, das türkische Meningoencephalitis Virus, ferner das Wesselsbron Virus, das Virus der biphasischen Meningoencephalitis und das durch Zecken oder durch Milch übertragene Virus der zentraleuropäischen Encephalitis und die Langat und Powassan Viren.

3. Gruppe G: Eine Gruppe von Arborviren, die von Menschen und von Affen, die als „Wachposten“ aufgestellt waren, und ferner auch von Moskitos im Amazonasgebiet in der Nähe von Belem isoliert werden konnten.

4. Bunyamwera Gruppe: Eine Gruppe von Arborviren, die von Mücken in verschiedenen Teilen der Welt isoliert werden konnten: Bunyamwera von Aedes in Ostafrika, Wyeomyia von W. melanocephala in Kolumbien, Kairi von Aedes scapularis in Trinidad, Cache Valley Virus von Culiseta inornata in Utah und von Aedes scapularis in Belem (Brasilien) und in Trinidad. Andere Viren dieser Gruppe, diekürzlich entdeckt wurden, sind das Chittoor Virus (Indien, Malaya), Germiston Virus (Südafrika), Guaroa Virus (Kolumbien, Brasilien) und Ilesha Virus (Westafrika).

5. Verschiedene Arborviren: Diese Gruppe enthält 9 Untergruppen, von denen jede aus 2 oder 3 Erregern besteht.

6. Nichtgruppierte Arborviren: Es gibt außerdem etwa 25 Virusarten, die keine Antigenverwandtschaft untereinander und keine Antigenverwandtschaft zu irgendeinem anderen Erreger, mit dem sie verglichen wurden, zeigen.

Unter den Viren der letzten beiden Gruppen, die tierische und menschliche Erkrankungen hervorrufen können, befindet sich das Virus des Colorado-Zeckenfiebers, des haemorrhagischen Fiebers der Krim, des argentinischen haemorrhagischen Fiebers (Junin Virus), des Rift Valley Fiebers, des Pappatacifiebers, des „Blue Tongue“ Fiebers, der Nairobi Schafkrankheit und der afrikanischen Pferdekrankheit. Diese letzte Virusart ist von ihrem ursprünglichen enzootischen Gebiet in Afrika über das östliche Mittelmeer nach Pakistan und Indien weitergewandert, wo sie 1960 allein über 50000 Todesfälle unter Pferden und eine unbekannte Anzahl von Erkrankungen hervorrief. Über eine evtl. Pathogenität für den Menschen ist noch nichts bekannt.

In den folgenden Abschnitten dieses Kapitels sollen einige der wesentlichsten Erkrankungen, die durch Arborviren beim Menschen hervorgerufen werden, näher besprochen werden.

\section{Encephalitiden durch Arborviren}

Encephalitiden können durch eine Vielzahl neurotroper Viren hervorgerufen werden. Diese Erreger führen zu einer Infektion, häufig in Epidemien, bei denen die klinischen Symptome Ausdruck des Befalls von Gehirn und Rückenmark sind. Derartige Erkrankungen mit gleicherartiger Epidemiologie hat man als durch Arthropoden übertragene Encephalitiden zusammengefaßt. Obwohl diese Erkrankungen viele Gemeinsamkeiten aufweisen, ist ihre geographische Verbreitung häufig äußerst unterschiedlich. So tritt die westliche Pferdeencephalitis (WEE) in den westlichen Teilen der USA und in Kanada auf, die östliche Pferdeencephalitis (EEE) findet sich dagegen in den östlichen und südlichen Teilen der USA. Die Venezuela Pferdeencephalitis beobachtet man in Südamerika und in Panama, die St. Louis Encephalitis in den mittleren und westlichen Teilen der USA, die japanische B- 
Encephalitis (Encephalitis japonica B) im fernen Osten (Japan, Korea, China, Malaya) und die Murray Valley Encephalitis in Australien.

Einer der Gründe für das auffällige Fehlen von Epidemien virusbedingter Encephalitiden im mittleren Osten kann das Vorherrschen des West Nile Virus in diesen Gebieten sein. Dieses Virus zeigt gemeinsame Antigenkomponenten und noch weitere Gemeinsamkeiten mit dem Virus der japanischen B-Encephalitis, der St. Louis und Murray Valley Encephalitis. Das Virus des West Nile Fiebers ist die Ursache einer milden, rasch abklingenden fieberhaften Erkrankung des Menschen. Die weite Verbreitung von West Nile Fieber im mittleren Osten hat vielleicht zu einer Steigerung der Resistenz in der Bevölkerung gegen jene Encephalitiden geführt, die durch das verwandte Virus der japanischen B-Encephalitis hervorgerufen werden. Mit anderen Worten, eine Bevölkerung, die gegen das West Nile Fieber immun ist, kann offenbar eine Epidemie, die durch eine verwandte Virusart - wie z. B. das Virus der japanischen B -Encephalitis - hervorgerufen wird, nicht unterstuitzen.

Andere Viren, wie z. B. das Gelbfieber, die Dengue und das West Nile Fieber besitzen gemeinsame Antigenkomponenten mit einzelnen Encephalitisviren und können sich bei Infektion von Laboratoriumstieren wie neurotrope Viren verhalten. Bei Infektionen des Menschen führen sie jedoch im allgemeinen nicht zu einer Erkrankung des Zentralnervensystems. Zahlreiche weitere Viren, wie Ntaya, Zika, Bunyamwera, Chikungunya, Ilheus und Turlock, die kürzlich aus Mücken in tropischen und subtropischen Gebieten isoliert werden konnten, verhalten sich bei Infektion von Laboratoriumstieren ebenfalls neurotrop, aber über die durch sie hervorgerufenen Krankheiten des Menschen weiß man nur wenig. Das Turlock Virus konnte von 3\% der in Kalifornien gefangenen Mücken isoliert werden.

Eine Encephalitis (oder Meningoencephalitis) kann ebenfalls als Komplikation bei einer Reihe von anderen Erkrankungen (Masern, Mumps, infektiöse Hepatitis, Pocken, Windpocken, Zoster u. a.) auftreten. Hierbei tritt der Befall des Zentralnervensystems offenbar als sekundäres Ereignis nach der Invasion in ein anderes Organ auf. Aus diesem Grunde hat man diese Encephalitiden auch als postinfektiöse bezeichnet.

\section{Eigenschaften der Viren}

A. Größe: Die Arborviren gehören zu den kleinen Viren, ihre Größe liegt schätzungsweise zwischen $20-50 \mathrm{~m} \mu$. Nach einzelnen Befunden scheinen die Viren der Gruppe der japanischen B-Encephalitis, der St. Louis und Murray Valley Encephalitis etwas kleiner $(20-30 \mathrm{~m} \mu)$ als die Viren der östlichen und westlichen Pferdeencephalitis $(30-50 \mathrm{~m} \mu) \mathrm{zu}$ sein. Einige dieser Viren hat man gereinigt und fand, daß sie Phospholipide, Fettsäuren und Cholesterin außer dem Nucleoprotein enthielten.

B. Verhalten gegenüber physikalischen und chemischen Einflüssen: Die Viren sind bei Zimmertemperatur instabil. Sie können durch Einfrieren bei $-70^{\circ} \mathrm{C}$, vor allem nach Zusatz von $50 \%$ Kaninchenserum aufbewahrt werden. Arborviren werden durch Galle oder durch 1:1000 Natriumdesoxycholat inaktiviert. Hierdurch können neu isolierte Viren ohne Schwierigkeit von den Enteroviren unterschieden werden, die gegenüber Desoxycholat resistent sind.

C. Empfänglichkeit verschiedener Tierarten und Vermehrung der Viren: Diese Viren sind für eine Vielzahl von Tieren infektiös; die Viren der östlichen und westlichen Pferdeencephalitis sind für eine große Zahl jährlich auftretender Erkrankungen bei Pferden und Eseln verantwortlich. Das meist verwendete Laboratoriumstier ist die Maus, die am einfachsten durch eine intracerebrale Inokulation infiziert werden kann. Vor allem sind saugende Mäuse für eine Infektion durch diese Viren empfänglich; mit zunehmender Reife der 
Tiere entwickelt sich im allgemeinen eine zunehmende Resistenz gegenüber einer experimentellen Infektion mit Ausnahme der nach intracerebraler Inokulation auftretenden. Bei Hühnern, Tauben, Enten, Fledermäusen, Meerschweinchen, Kaninchen und Affen kann man durch Verimpfung kleiner Virusmengen in die Haut der Tiere eine inapparent ablaufende Infektion erzeugen, während der das Virus mehrere Tage lang im Blut kreist. In der Natur ist diese Art der Infektion als Quelle des Virus für die Insekten, die wiederum als Vektor der Erkrankung dienen, anzusehen.

Nach Inokulation in den Dottersack oder die Chorioallantois vermehren sich diese Viren auch in embryonierten Hühnereiern. Ferner können sie ohne Schwierigkeiten in Gewebekulturen aus Mäuse- oder Hühnerembryonen oder in Zellinien aus Säugetierzellen vermehrt werden. Hierbei kann man die Virusvermehrung durch die direkte Beobachtung der cytopathischen Veränderungen und durch Anwendung der virusspezifischen Immunofluoreszenz, ferner durch die Bildung von Virushämagglutinin, das direkt in der Gewebekultur durch den Hämadsorptionstest bestimmt wird, verfolgen. Durch Verwendung der Plaquetechnik hat man angeblich besser reproduzierbare und empfindlichere Teste mit den Viren der Gruppe A, B und C in Gewebekulturen von Hühnerembryonen bzw. Enten- oder Affennieren entwickelt.

D. Antigeneigenschaften: Es lassen sich komplementbindende Antigene und Hämagglutinine präparieren, wobei als Ausgangsmaterial im allgemeinen das Hirn infizierter saugender Mäuse wegen seines geringen Fettgehaltes verwendet wird. Die Hämagglutinine dieser Viren sind Teil des infektiösen Viruspartikels. Die Bindung zwischen Hämagglutinin und Erythrocyt ist irreversibel. Der Erythrocyt-Virus-Komplex ist noch infektiös, kann aber durch den Zusatz von Antiseren neutralisiert werden, was zur Ausbildung von großen Gitterstrukturen führt. Dieses Phänomen, zusammen mit dem Verlust der Infektiösität im alkalischen $\mathrm{pH}$ Bereich, während die hämagglutinierende Fähigkeit bei saurem $\mathrm{pH}$ zerstört wird, zeigt, daß die für die Infektiosität und für die Hämagglutination verantwortlichen Stellen auf dem Virus unterschiedlich sind.

Einige dieser Viren weisen eine überlappende Antigenität auf, die am einfachsten durch eine Kreuzreaktion mit dem Hämagglutinationshemmungstest aufgezeigt werden kann. Diese Überlappung beruht auf der Gegenwart von einem oder auch von mehreren kreuzreagierenden Antigenen, die außer den Stamm-spezifischen Antigenen vorhanden sind. Aus diesem Grunde besitzen Immunseren, die gegen einen Stamm gerichtet sind, sowohl stammals auch gruppenspezifische Antikörper.

Durch Adsorption der Immunseren mit heterologen Viren der gleichen Gruppe kann man spezifische Seren erhalten. Diese Antiseren reagieren im Hämagglutinationshemmungstest nur noch mit dem homologen, dagegen nicht mehr mit dem heterologen Stamm. Durch Verwendung derartiger, adsorbierter Seren wurde die Analyse der komplexen Antigenenstruktur einiger Arborviren innerhalb der großen Gruppen sowie die Identifizierung neu isolierter Stämme möglich.

\section{Pathogenese und Pathologie}

Die Pathogenese der menschlichen Erkrankung ist nur unzureichend untersucht, aber in einigen Fällen kann die Erkrankung des experimentell infizierten Tieres als Modell für die menschliche Erkrankung herangezogen werden. So zeigt sich, daß z.B. die Pferdeencephalitiden beim Pferd biphasisch verlaufen. In der ersten Krankheitsphase (minor illness) vermehrt sich das Virus in den nicht-neuralen Geweben und ist 3 Tage vor den ersten Anzeichen einer ZNS-Beteiligung im Blut nachweisbar. In der zweiten Phase (major illness) vermehrt sich das Virus im Gehirn, hierbei werden Zellen geschädigt, zerstört und die Encephalitis wird auf klinischer Ebene apparent. Wie auch bei der Poliomyelitis, können 
diese zwei Phasen streng unterschieden sein oder sich auch gegenseitig überlappen. Es ist unklar, wie das Virus in das Zentralnervensystem eindringt; hierüber gibt es 3 verschiedene Ansichten: 1. Das Virus dringt direkt in das ZNS aus dem Blut ein. 2. Das Virus dringt aus dem Blut in die Nasenschleimhaut ein und wird von hier auf dem Wege über die Neuronen in das ZNS transportiert. 3. Von der Stelle des Eindringens in den menschlichen Organismus geht das Virus auf dem Wege über die Nervenfasern direkt in das ZNS.

Bevor die klinische Erkrankung manifest wird, müssen bestimmte Viruskonzentrationen im Gehirngewebe erreicht werden. Das Ausmaß, in dem sich das Virus im Gehirn vermehrt, wird bei Mäusen sowohl durch genetische (im Sinne der MENDEL' schen Gesetze) als auch durch andere Faktoren beeinflußt.

Die primären Encephalitiden sind durch Läsionen in allen Teilen des ZNS charakterisiert, die stärksten Veränderungen finden sich in den nasalen Strukturen des Gehirns und in der Großhirnrinde. Stets erkennt man perivasculäre und meningeale Infiltrationen, die vorwiegend aus Lymphocyten bestehen. Im zerebralen Cortex, in der Kleinhirnrinde, in den Basalganglien, der Pons, der Medulla und in den oberen Rückenmarksabschnitten treten Nervenzelldegenerationen mit Neuronophagien auf. Vor allem bei der Encephalitis japonica B können die PURKINJE-Zellen des Kleinhirns zerstört sein. Außerdem können encephalomalazische Herde auftreten; zellfreie Plaques mit einer schwammartigen Struktur, in denen die markhaltigen Fasern, die Dendriten und Axone zerstört sind, lassen sich ebenfalls feststellen. Auch beobachtet man fokale Mikrogliaproliferationen. Es sind also nicht nur die Neurone, sondern auch die Zellen des Stützgewebes des ZNS in Mitleidenschaft gezogen. Die Läsionen im Rückenmark sind denen, die durch Poliomyelitisviren hervorgerufen werden, sehr ähnlich. Aus diesem Grunde ist es nicht möglich, eine Poliomyelitis von den Virusencephalitiden allein durch eine histologische Untersuchung des Rückenmarks zu unterscheiden; die Veränderungen im Gehirn sind jedoch deutlich verschieden.

Die Erreger der japanischen Encephalitis B oder der westlichen Pferdeencephalitis dringen in den Körper durch den Biss einer infizierten Mücke ein. Von dieser Eintrittsstelle gelangen sie in das ZNS, wo sie sich festsetzen. Es konnte bisher nicht festgestellt werden, $\mathrm{ob}$ es beim Menschen eine primäre Virusvermehrung im Intestinum gibt, der eine sekundäre Freisetzung des Virus in das Blut folgt bevor der Erreger in das ZNS eindringt. Bei experimentellen Infektionen hat man feststellen können, daß sich das Virus in dem nichtneuralen Gewebe infizierter Affen vermehrt.

\section{Klinische Symptome}

Die Inkubationszeit der Virusencephalitiden wird auf 4-21 Tage geschätzt. Die Erkrankungen sind durch einen plötzlichen Beginn mit Kopfschmerzen, Schüttelfrost, Fieber, Schwindelgefühl und Erbrechen gekennzeichnet, außerdem bestehen allgemeine Schmerzen und ein deutliches Krankheitsgefühl. Innerhalb von 24-48 Stunden nach Beginn kann sich eine deutliche Schläfrigkeit entwickeln, die bis zu einer Bewußtlosigkeit fortschreiten kann. Häufig findet sich eine Nackensteife. In schweren Fällen entwickeln sich Verwirrtheitssymptome, Sprachschwierigkeiten, Tremor, Krämpfe und ein Koma. Die Sterblichkeitsrate schwankt bei den meisten Encephalitiden zwischen 5 und 25\%, sie kann aber bis zu $40 \%$ betragen. Bei der japanischen Encephalitis B hat man eine Letalität bei älteren Menschen von $80 \%$ beobachtet. Dauerschäden sind häufig; Intelligenzdefekte, Blindheit, Taubheit, Epilepsie oder Paralysen können auftreten. Abortive Infektionen ähneln einer abakteriellen Meningitis und sind schwierig von einer nicht-paralytischen Poliomyelitis zu unterscheiden. In einigen Gegenden scheinen inapparente Infektion häufig aufzutreten.

In den Gebieten, wie z.B. Kalifornien, wo sowohl die westliche Pferdeencephalitis( WEE) als auch die St. Louis Encephalitis (SLE) vorkommen, zeigt die WEE eine Prädilektion für 
das Kleinkindes- und Kindesalter. Etwa $75 \%$ der Fälle treten bei Kindern unter 10 Jahren auf und $50 \%$ bei Kindern im ersten Lebensjahr. Bei einem Ausbruch dieser Erkrankung wurden $\mathbf{7 0 \%}$ der kindlichen Erkrankungsfälle bei Kindern im ersten Trimenon beobachtet. In dem gleichen Gebiet tritt die SLE nur selten bei Kleinkindern auf, obwohl beide Viren durch den gleichen Vektor (Culex tarsalis) übertragen werden.

\section{Laboratoriumsdiagnose}

A. Isolierung des Virus: Das Virus tritt im allgemeinen nur früh im Infektionsablauf und vor Einsetzen der Symptome im Blut auf. Am häufigsten kann es aus dem Gehirn bei tödlich verlaufenen Erkrankungen isoliert werden. Derartige Untersuchungsproben sollten unter sterilen Kautelen sobald wie möglich nach dem Exitus entnommen werden. Sie werden zu einer $20 \%$ Suspension in physiologischer Kochsalzlösung verarbeitet und 0,03 ml werden intracerebral in junge und neugeborene Mäuse verimpft. Man kann auch bebrütete Hühnereier für die Virusisolierung verwenden.

Konnte ein vermehrungsfähiges Agens - frei von Bakterien - aus den Gehirnen der geimpften Mäuse erhalten werden (oder in Hühnerembryonen), so muß dieses Agens durch entsprechende Neutralisation oder Komplementbindung oder Hämagglutinationshemmung mit bekannten Antiseren identifiziert werden. Um das Hämagglutinin von Arborviren nachzuweisen, muß man Erythrocyten von 1 Tage alten Kücken verwenden oder wie man kürzlich festgestellt hat - Erythrocyten von Gänsen benutzen. Eine weniger gebräuchliche Methode zur Identifizierung der Viren ist die Inokulation des unbekannten Erregers in verschiedene Mäusekollektive, die vorher gegen einzelne bestimmte Virusarten immunisiert worden waren.

B. Serologie: Innerhalb einer Woche nach Beginn der Erkrankung sind sowohl neutralisierende als auch komplementbindende Antikörper nachweisbar. Die neutralisierenden Antikörper bleiben jahrelang, wenn nicht lebenslänglich, nachweisbar. Der komplementbindende Antikörper ist weniger dauerhaft und kann innerhalb von 1-2 Jahren nach der Infektion verschwinden.

Der einfachste serodiagnostische Test bei derartigen Erkrankungen ist der Hämagglutinationshemmungstest, aber hierdurch wird im wesentlichen dieGruppe und weniger das einzelne ätiologisch verantwortliche Virus identifiziert. Verwendet man Erythrocyten von erwachsenen Gänsen und nicht von frisch geschlüpften Kücken, so muß das zu untersuchende Serum zuerst mit Gänseerythrocyten adsorbiert werden, um das in menschlichen und anderen Seren vorhandene unspezifische Hämagglutinin zu adsorbieren.

In gleicher Weise wie bei anderen Infektionen ist es auch hier erforderlich, während der Infektion einen Anstieg der spezifischen Antikörper festzustellen, um eine Diagnose zu ermöglichen. Aus diesem Grund muß die erste Serumentnahme sobald wie möglich nach Beginn der Erkrankung und die zweite Entnahme etwa 3-4 Wochen später erfolgen. Beide Serumentnahmen müssen in dem gleichen serologischen Test untersucht werden.

Bei der Diagnose müssen die Kreuzreaktionen innerhalb der Gruppe A oder B der Arborviren in Betracht gezogen werden. So können sich nach einer Infektion durch ein Virus der einen Gruppe auch Antikörper gegen die anderen Mitglieder dieser Gruppe entwickeln. Als Regel kann jedoch gelten, daß die höchsten Antikörpertiter gegen das Virus bestehen, das die jetzige Erkrankung verursacht. Die Spezifität der Antikörper im Hinblick auf das ätiologisch verantwortliche Virus nimmt in der Reihenfolge neutralisierender Antikörper, komplementbindender Antikörper und hämagglutinationshemmender Antikörper ab. 


\section{Immunität}

Man nimmt an, daß die Immunität nach einer einzigen Infektion dauerhaft ist. In endemischen Gebieten kann man eine Immunität als Folge inapparenter Infektionen erwerben. Die Häufigkeit von Menschen mit Antikörpern gegen die lokal verbreiteten Arborviren nimmt mit zunehmendem Alter zu.

Versuche zu einer Immunisierung mit Totvakzinen aus Mäusehirn oder Hühnerembryonen haben beim Menschen noch nicht zu eindeutigen Resultaten geführt, obwohl diese Vakzinen in der Lage sind, bei der Maus die Bildung von Antikörpern und auch einen Schutz zu erzeugen.

Da verschiedene Mitglieder einer Arborvirusgruppe gemeinsame Antigene besitzen, wird die Antikörperbildung bei einer Immunisierung (oder Infektion) durch ein Virus dieser Gruppe durch frühere Exposition gegenüber anderen Viren dieser Gruppe modifiziert. Im allgemeinen ist die homologe Reaktion stärker als die kreuzreagierenden Reaktionen. Inokuliert man Tieren wiederholt ein Virus der Gruppe A oder B, so verleiht man den Tieren auch einen Schutz gegen andere Viren der gleichen Gruppe, vor allem wenn die spätere Belastungsinokulation durch eine periphere Injektion erfolgt.

Japaner, die in ihrer Anamnese keine Encephalitis angeben, aber trotzdem neutralisierende Antikörper gegen das Virus der japanischen B-Encephalitis aufweisen ohne daß komplementbindende Antikörper nachweisbar wären, reagieren auf eine einzige Injektion einer Vakzine mit geringer Wirksamkeit mit einem deutlichen Anstieg der komplementbindenden Antikörper. Diese Vakzine gegen das Virus der japanischen B-Encephalitis kann von so geringer Wirksamkeit sein, daß sie allein weder neutralisierende noch komplementbindende Antikörper in entsprechenden Kontrollen hervorrufen kann.

\section{Behandlung}

Es gibt keine allgemein anerkannte spezifische Behandlung. Die Anwendung von Hyperimmunseren ist bei Tierversuchen ohne Erfolg, wenn das Serum nach Einsetzen der Krankheitssymptome gegeben wird. Wird es dagegen 1-2 Tage nach dem Eindringen des Virus verabreicht, bevor Zeichen einer Encephalitis erkennbar sind, so kann das Serum den tödlichen Ausgang der Erkrankung verhindern.

\section{Epidemiologie}

Bei schwer verlaufenden, durch Encephalitisviren hervorgerufenen Epidemien kann die Erkrankungsrate etwa $2-3$ pro 1000 betragen. Bei kleinen Ausbrüchen, wie z.B. 1955 in Kentucky, kann diese Erkrankungsrate sogar noch höher liegen. In einer Bevölkerung von 1500 Personen traten 13 klinische Fälle auf, von denen 2 tödlich verliefen. $16 \%$ der Bevölkerung wurden inapparent infiziert.

Die meisten Arborvirusinfektionen treten ausschließlich bei Säugetieren oder Vögeln auf, der Mensch ist hier nur als zufälliger Wirt anzusehen. Man kann die Viren aus Mücken, Zecken und Milben isolieren und diese Arthropoden sind auch als die hauptsächlichen Vektoren für die Virusübertragung anzusehen, gelegentlich können sie auch ein Reservoir für die Infektion bilden.

Die Epidemiologie der durch Arthropoden übertragenen Encephalitiden muß die Verbreitung und Erhaltung dieser Virusarten in der Natur auch in Abwesenheit des Menschen erklären. Das Virus wird von den infizierten Tieren durch den Biß eines als Vektor dienenden Arthropoden übertragen. Bei einigen Arthropoden kann das Virus von der einen Generation auf die nächste transovariell weitergegeben werden und in diesen Fällen dienen die Zecken oder Milben sowohl als echtes Reservoir der Viren und auch als ihr Überträger. 
Bei Mücken (Culex pipiens und Aedes albopictus) konnte eine transovarielle Übertragung bisher nur fuir das Virus der japanischen B-Encephalitis nachgewiesen werden.

Bisher konnte nicht geklärt werden, warum Arborviren nur in bestimmten geographischen Gebieten stets vorhanden sind. Es ist z.B. unklar, ob dieses Virus in jedem Jahr neu von außen eingeschleppt wird, z. B. durch Vögel, die aus tropischen oder südlichen Gebieten einwandern oder ob das Virus in dem jeweiligen Gebiet irgendwie überwintert. Man könnte sich einen verhältnismäßig einfachen Mechanismus der Überwinterung in Form der den Winter überlebenden Mücken vorstellen, die die Vögel bei ihrem Erscheinen im Frühjahr dann erneut infizieren und dadurch jedes Jahr zu einem einfachen Vogel - Mükken - Zyklus führen könnten. Es ist auch denkbar, daß das Virus während dieser Jahreszeit in Säugetieren oder Arthropoden latent bleibt. Mehrere Monate nach der Infektion von Vögeln mit verschiedenen Arborviren konnte aus dem Gehirn und der Milz dieser Tiere Virus isoliert werden, auch nachdem sie bereits Serumantikörper gebildet hatten.

Bei Schlangen, denen WEE inokuliert worden war, konnte im folgenden Frühjahr im Blut zirkulierendes Virus in hohen Konzentrationen nachgewiesen werden. Normale Mükken konnten durch Füttern an diesen Schlangen nach der Überwinterung infiziert werden und dann das Virus wiederum auf Hühner übertragen. Diese Angaben zeigen einen möglichen Mechanismus der Überwinterung von Arborviren; dem steht aber entgegen, daß bisher keine Viren von wildlebenden Schlangen isoliert werden konnten.

A. Serologische Epidemiologie: Untersuchungen über die Verbreitung von Antikörpern in der normalen Bevölkerung haben gezeigt, daß in endemischen Gebieten fast die gesamte Bevölkerung infiziert worden ist und daß der größte Teil dieser Infektionen asymptomatisch verlief. Diese Angaben treffen für die japanische B-Encephalitis in Japan, Korea und auf Okinawa zu. Größere Epidemien traten unter der eingeborenen Bevölkerung in Korea nicht auf, obwohl gelegentliche Erkrankungen bei den dort stationierten Amerikanern beobachtet wurden. Auch bei Haustieren (Schweine, Kühe und Pferde) verläuft ein großer Teil der Infektionen inapparent. Anläßlich einer Epidemie mit Murray Valley Encephalitis hat man geschätzt, daß eine klinisch manifeste Erkrankung auf jeweils 700 inapparente Infektionen oder auch Infektionen mit angedeuteter Symptomatik kommt. Bei der bereits erwähnten Epidemie von St. Louis Encephalitis in Kentucky fand sich zusätzlich zu der klinisch manifesten Erkrankung eine inapparente Infektionsrate von 16\% in der Bevölkerung. Antikörper gegen diesen Erreger waren ferner bei mehr als der Hälfte der untersuchten Hühner, Pferde und der wildlebenden Vögel in diesem Gebiet nachzuweisen.

In Endemiegebieten, wie z. B. Kalifornien werden $11 \%$ der Kinder mit Antikörpern gegen WEE geboren und $27 \%$ besitzen Antikörper gegen SLE. Zwischen der Länge des Aufenthaltes der Mutter in diesem endemischen Gebiet und dem Erwerb von Antikörpern gegen die Erreger besteht eine direkte Beziehung.

B. Durch Mücken übertragene Encephalitiden: Es kommt zur einer Infektion des Menschen, wenn Mücken wie Culex tarsalis, Culex pipiens oder Culex gelidus (Japan) oder auch andere Arthropoden zuerst ein infiziertes Tier und danach einen Menschen stechen. Für die Pferdeencephalitiden nimmt man einen Zyklus an, bei dem die Milbe, durch die das Virus in der Natur verbreitet wird, gelegentlich Vögel heimsucht. Kommt es dan zu einer Virämie bei dem infizierten Vogel, so wird während des Saugens eine Mücke infiziert und überträgt das Virus auf andere Vögel, Pferde oder auch auf den Menschen. In einer Epidemie können Mücken als Überträger wirken, da sie infizierte Menschen oder Pferde stechen und dann anschließend auf neuen Wirten saugen. Man nimmt an, daß so oder ähnlich die Epidemiologie der Pferdeencephalitiden, der japanischen B-Encephalitis, der St.Louis Encephalitis und der Murray Valley Encephalitis abläuft. 
Offenbar können nur bestimmte Wirbeltiere als Wirte der verschiedenen Arborviren in Frage kommen. So vermehrt sich das Virus der westlichen Pferdeencephalitis nur in Vögeln ausreichend, um die Übertragung auf Mücken zu ermöglichen; dagegen vermehrt sich das Virus der Venezuela Pferdeencephalitis am besten in Säugetieren. Das Virus der östlichen Pferdeencephalitis kann sich in beiden Wirten vermehren, obwohl offenbar bei Vögeln eher ausreichende Virustiter im Blut auftreten, um eine Übertragung auf die Mükken zu ermöglichen.

Eine Arborvirusinfektion bei Insekten-fressenden Fledermäusen verursacht eine Virämie, die etwa 6-12 Tage dauert, ohne daß die Tiere irgendwelche Krankheitssymptome oder pathologische Veränderungen zeigen. Infizierte Mücken können im Experiment ohne Schwierigkeiten bei normalen Fledermäusen Blut saugen und hierdurch das Virus auf diese Tiere übertragen. Bei diesen Fledermäusen entwickelt sich dann eine Virämie und nachdem die Viruskonzentration hoch genug ist, kann die infizierte Fledermaus wiederum als Infektionsquelle für andere Mücken dienen, die die Infektion auf Hühner sowie auf weitere Fledermäuse übertragen können.

In der Natur leben die Mücken mit den Fledermäusen in einer engen Gemeinschaft, nicht nur im Sommer während des Tages auf den Rastplätzen, sondern auch bei der Überwinterung in Höhlen. In einem Experiment, das die Bedingungen ciner Hibernation in Höhlen imitierte, waren die Mücken in der Lage, das Virus auf die Fledermäuse unter bestimmten Voraussetzungen zu übertragen. Hierzu mußten sie eine entsprechende externe Inkubationszeit bei $27^{\circ} \mathrm{C}$ vor Senkung der Temperatur durchmachen. Die hierbei infizierten Fledermäuse zeigten ohne Auftreten einer Virämie eine latente Infektion, die 3 Monate lang bei $10^{\circ} \mathrm{C}$ unter diesen imitierten Überwinterungsbedingungen nachweisbar war. Unmittelbar nachdem man die Fledermäuse in eine normale Raumtemperatur zurïckgebracht hatte. konnte kein Virus nachgewiesen werden; aber 3 Tage später fand sich bei diesen Tieren eine Virämie. Die nach der Hibernation bei den Tieren festgestellten Virustiter lagen oberhalb des zur Infektion von Mücken erforderlichen Minimalwertes. Dieser MückeFledermaus - Miicke - Zvklus kann somit vielleicht auch als ein Mechanismus für die Überwinterung der Arborviren angesehen werden.

\section{Durch Zecken übertragene Encephalitiden:}

1. Russische Frühjahrs-Sommer-Encephalitis: Diese Erkrankung tritt hauptsächlich im Frühsommer, vor allem bei erwachsenen Männern auf, die mit der Zecke Ixodes persulcatus in verwilderten Wäldern in Berührung gekommen sind. Zecken können in jedem Stadium ihrer Metamorphose infiziert werden und das Virus anschließend transovariell übertragen. Man nimmt an, daß das Virus in der Zecke überwintert. Außer dem Menschen können auch Vögel und Tiere infiziert werden; infizierte Ziegen scheiden das Virus mit der Milch während eines langen Zeitraums aus. Die Infektion kann auf diesem Wege auf Menschen übertragen werden, die diese Milch trinken.

2. Looping ill: Diese Erkrankung der Schafe in Schottland und im nördlichen England wird durch die Zecke Ixodes ricinus übertragen. Gelegentlich kann auch der Mensch infiziert werden.

3. Tschechoslowakische Encephalitis und schwedische Meningoencephalomyelitis: In ihrer Antigenität sind diese Viren mit dem Virus der russischen Frühjahrs-Sommer-Encephalitis und dem Looping ill Virus verwandt.

4. Kyasanur Waldkrankheit: Diese in Indien auftretende haemorrhagische Erkrankung zeigt eine gewisse Ähnlichkeit mit dem haemorrhagischen Fieber von Omsk; beide Erkrankungen werden durch Viren der Gruppe der russischen Frühjahrs-Sommer-Encephalitis 
verursacht. In den südlichen Teilen Indiens können gelegentlich verschiedene Affenarten (Presbytis entellus, Macaca radiata) durch diese Erreger natürlich infiziert werden.

5. Powassan Encephalitis: Dieses durch Zecken übertragene Virus gehört ebenfalls zur Gruppe der russischen Frühjahrs-Sommer-Encephalitis. Es ist das erste Virus dieser Gruppe, das in Nordamerika (Kanada 1959) gefunden wurde.

Jedes Virus ist auf ein bestimmtes Gebiet begrenzt. Viele Viren der gleichen Gruppe weisen jedoch außer der bereits beschriebenen Überlappung bei immunologischen Reaktionen noch weitere Gemeinsamkeiten auf, wie Größe, Gewebstropismus und jahreszeitlich gebundenes Auftreten. Man hat angenommen, daß diese Viren auf eine gemeinsame Vorstufe zurückgehen und dann an verschiedene Gegenden der Welt adaptiert wurden, wobei jedes Virus seinen speziellen Arthropoden als Überträger und sein tierisches Reservoir besitzt. Auf der anderen Seite ist es möglich, ein Virus aus einem bestimmten Gebiet herauszuhalten, da das hier verbreitete lokale Virus eine Immunität in der Bevölkerung aufgebaut hat, die wegen der überlappenden serologischen Reaktionen auch gegen andere Viren schützt. Hierdurch wird vielleicht der mittlere Osten, wo West Nile Fieber vorherrscht, aus dem Verbreitungsgebiet der japanischen B-Encephalitis ausgespart.

Ähnliche Verhältnisse kann man auch im Gebiet der Karibischen See antreffen, wo die Dengue eine allgemein verbreitete Infektion ist und wo die Antikörper gegen die DengueViren einen Schutz gegen das Gelbfieber-Virus bieten. Dies mag die Ursache dafür sein, daß das Gelbfieber-Virus in Indien niemals Fuß fassen konnte. Eine Infektion durch ein Virus dieser Gruppe ruft nicht nur eine Antikörperbildung gegen den infizierenden Erreger hervor, sondern auch gegen die übrigen Mitglieder der Gruppe. Da jedoch Gelbfieberinfektionen auch bei solchen Menschen auftreten, die früher bereits durch Dengue- und Ilheus Virus infiziert wurden, muß man annehmen, daß diese Immunität gegenüber dem zweiten Erreger nur relativ ist. Immerhin spricht die rasche Bildung hoher Antikörpertiter gegen eine Vielzahl von Viren dafür, daß diese Menschen relativ immun sind, d.h. sie können bei einer Exposition gegenüber dem heterologen Virus mit der Infektion besser fertig werden als solche Menschen, die keine derartige frühere Exposition hatten.

\section{Kontrolle}

In den Gebieten, in denen diese Krankheiten vorkommen, ist die Vernichtung der als Überträger dienenden Arthropoden eine logische Kontrollmaßnahme. Durch die Verabreichung von Virus, das durch Formalin und UV-Licht inaktiviert wurde, konnte bei Tieren eine Antikörperbildung angeregt werden und eine Immunität erzeugt werden. Die Anwendung der Vakzine in Feldversuchen bei Menschen hatte jedoch nicht den gleichen Erfolg, wenn man auch bei japanischen Kindern ermutigende Resultate erhalten hatte. Die Entwicklung von abgeschwächten Stämmen durch fortlaufende Passagen des Virus in Kulturen verschiedener Zelltypen befindet sich noch im experimentellen Stadium, so daß Lebendvakzinen aus abgeschwächten Viren gegenwärtig nicht zur Verfügung stehen. Hierbei muß beachtet werden, daß diese abgeschwächten Stämme nach weiteren Passagen in Tieren virulente Mutanten erzeugt haben.

\section{West Nile Fieber}

West Nile Fieber ist eine akute, milde, fieberhafte Erkrankung, die mit einer Lymphadenopathie und einem Exanthem einhergeht. 


\section{Eigenschaften des Virus}

Das Virus besitzt die Eigenschaften der übrigen Arborviren der Gruppe B. Es vermehrt sich im Hühnerembryo und in Gewebekulturen, wobei es Plaques auf einschichtigen Zellkulturen unter Agar bildet. Von allen Viren der Gruppe B zeigt es die größte antigene Überlappung mit den Viren aus den Speicheldrüsen von Fledermäusen in Texas.

\section{Klinische Befunde}

Das Virus wird durch den Stich einer Mücke der Gattung Culex übertragen. Der Erreger führt zu einer Virämie und einer generalisierten Infektion, die durch eine Lymphadenopathie gekennzeichnet ist und gelegentlich von einem makulo-papulösen Exanthem begleitet wird. Selten kann es auch einmal zu einer vorübergehenden meningealen Reizung während des akuten Krankheitsstadiums kommen; hierbei steigt die Zellzahl und der Eiweißgehalt im Liquor. Bei alten Menschen, die eine verlangsamte und erniedrigte Antikörperbildung zeigen, kann dieser Erreger auch einmal zu einer tödlich endenden Encephalitis führen.

\section{Laboratoriumsdiagnose}

Zur Isolierung des Virus wird Blut im akuten Stadium der Infektion entnommen. Zur Durchführung serologischer Tests muß die erste (negative) Blutprobe so früh wie möglich im Krankheitsablauf entnommen werden, während die zweite etwa 2-3 Wochen später gesammelt wird. Es wird die Durchführung einer Komplementbindungsreaktion empfohlen, obwohl der Hämagglutinationshemmungstest und der Neutralisationstest ebenfalls verwendet werden können. In den während der Rekonvaleszenz entnommenen Blutproben findet man in der Komplementbindungsreaktion im allgemeinen Titer von 1:32 bis 1:128. Die Antikörper bleiben in dieser Titerhöhe etwa 3 Monate lang nachweisbar und fallen dann langsam in den nächsten 2 Jahren auf niedrigere Titerwerte ab. Die homologen neutralisierenden Antikörper steigen etwas langsamer an, erreichen ihre höchste Titerhöhe nach etwa 4 Monaten und bleiben etwa 2 Jahre lang in dieser Titerhöhe bestehen. Während der Rekonvaleszenz entwickeln sich heterologe komplementbindende und neutralisierende Antikörper gegen die japanische B-Encephalitis und die St. Louis Encephalitis, jedoch nicht gegen die Viren der Pferdeencephalitiden. Die mit Hilfe der Komplementbindungsreaktion nachweisbaren heterologen Antikörper sind im allgemeinen nur in niedrigeren Titern und auch nur eine kürzere Zeit als die homologen Antikörper nachweisbar. Die heterologen neutralisierenden Antikörper gegen das Virus der japanischen B-Encephalitis erreichen jedoch annähernd gleich hohe Titer wie die homologen, gegen das West Nile Virus gerichteten Antikörper. Gegen Ende des ersten Jahres nach Beginn der Erkrankung fallen die heterologen Antikörper jedoch auf niedrigere Titer ab und verschwinden etwa nach $2 \frac{1}{2}$ Jahren vollständig.

\section{Immunität}

Eine Vakzine aus inaktivierten Viren der japanischen B-Encephalitis führt im allgemeinen nicht zu einer guten Antikörperbildung gegen diesen Erreger. Sensibilisiert man jedoch Freiwillige zuerst durch die milde verlaufende West Nile Infektion und verabreicht danach die aus abgetöteten Viren bestehende Vakzine gegen das Virus der japanischen B-Encephalitis, so bilden sich hohe Titer neutralisierender Antikörper gegen das Virus der japanischen B-Encephalitis und niedrige Titer gegen die verwandten Arborviren der Gruppe B. Man kennt nur einen Antigentyp und die Immunität gegen diesen Erreger ist wahrscheinlich dauerhaft. Mütterliche Antikörper werden von der Mutter auf das Neugeborene übertragen, sie verschwinden während der ersten 6 Monate des Lebens. 


\section{Epidemiologie}

West Nile Fieber scheint auf den mittleren Osten beschränkt zu sein. Sporadisch wurde der Erreger in Ägypten und während Epidemien in Israel isoliert. Antikörper gegen den Erreger konnte man jedoch bei normalen Erwachsenen in Afrika, Indien und in Korea nachweisen. Die Befallsrate ist in einer nicht immunen Bevölkerung sehr hoch, auch abortive und inapparente Infektionen treten auf. In einigen Gebieten wie z.B. in Kairo herrschen die inapparenten Infektionen vor, wo über $70 \%$ der Einwohner im Alter von 4 Jahren und älter neutralisierende und komplementbindende Antikörper gegen dieses Virus besitzen. Ein dem West Nile Virus nahe verwandte Erreger (im Hinblick auf die Antigenität) wurde aus den Speicheldrüsen von Fledermäusen (Tadarida mexicana) in Texas isoliert.

Diese Sommerkrankheit tritt in ländlichen Gebieten häufiger als in Städten auf. Aus Culex konnte bei verschiedenen Gelegenheiten während epidemischer Häufungen von Erkrankungen dieses Virus isoliert werden. Die Mücken sind auch im Laboratorium infizierbar; nach einer externen Inkubationszeit von 1-3 Wochen können sie die Erkrankung übertragen. Wenn man das Virus aus Mücken in endemischen Gebieten im Sommer isolieren kann, so findet man es in dieser Zeit auch im Blut fieberhaft erkrankter Kinder.

Auch Zecken können als Reservoir und als Überträger des West Nile Fiebers von Bedeutung sein. Nymphen der Zecke Ornithodoros moubata können durch Saugen an Mäusen während der virämischen Phase infiziert werden. Das Virus vermehrt sich in der Nymphe und bleibt in der reifen Imago mindestens 224 Tage lang nachweisbar. Die Zecken können wiederum das Virus auf Hühner und Mäuse durch den Saugakt übertragen.

\section{Kontrolle}

Eine Mückenbekämpfung ist die logische Kontrollmaßnahme, die sich bis jetzt allerdings noch nicht als wirksam erwiesen hat.

\section{Gelbfieber}

Gelbfieber ist eine akute, fieberhafte durch Mücken übertragene Erkrankung. Schwere Krankheitsfälle sind durch Gelbsucht, Proteinurie und Haemorrhagien charakterisiert.

\section{Eigenschaften des Virus}

A. Größe: Das Gelbfieber-Virus besitzt einen Durchmesser von etwa 18-25 m $\mu$.

B. Verhalten gegenüber chemischen und physikalischen Einflüssen: Das Virus kann etwa einen Monat lang bei $4^{\circ} \mathrm{C}$ aufbewahrt werden, 3 Monate lang in $50 \%$ Glycerin bei $\mathrm{O}^{\circ} \mathrm{C}$ und jahrelang bei $-70^{\circ} \mathrm{C}$. Nach Auftrocknen aus dem gefrorenen Zustand bleibt es bei $\mathrm{O}^{\circ} \mathrm{C}$ jahrelang infektiös. Das Virus wird durch $10 \mathrm{Min}$. langes Erhitzen auf $65^{\circ} \mathrm{C}$ abgetötet und ebenfalls durch eine 48 Stunden lange Einwirkung von $0,1 \%$ Formalin bei $\mathrm{O}^{\circ} \mathrm{C}$ inaktiviert. Ferner wird es sehr rasch durch Verdünnen in physiologischer Kochsalzlösung inaktiviert; das kann durch einen Zusatz von 5\% Normalserum zu dem Verdünnungsmedium verhindert werden.

C. Empfänglichkeit von Tieren und Vermehrung des Virus: Das Gelbfiebervirus vermehrt sich in einer Vielzahl verschiedener Tiere (Affen, Mäuse, Meerschweinchen und Igel), ferner kann es sich auch in Mücken vermehren. Der Erreger ist ohne Schwierigkeiten in embryonierten Hühnereiern und in Gewebekulturen aus embryonalen Hühner- und Mäusezellen zu vermehren. Alle Stämme führen nach intracerebraler Inokulation von Mäusen zu 
einer Encephalitis. Dieser Encephalitis tritt bei jugendlichen Mäusen auch nach subkutaner und intraperitonealer Inokulation auf.

Frisch isolierte Virusstämme (von Menschen, Affen oder Mücken) verhalten sich pantrop, d.h. sie befallen alle drei embryonalen Zellagen. Diese Stämme fuihren nach subkutaner und intraperitonealer Inokulation von Affen zu einer schweren (im allgemeinen tödlich verlaufenden) Infektion mit einem deutlichen Leberschaden. Nach fortlaufender Hirn- zu Hirnpassage bei Affen und Mäusen verlieren solche Stämme viel von ihrem Viscerotropismus. Sie führen nach intracerebralen Inokulation dann zu einer Encephalitis, nach subkutaner Infektion jedoch lediglich zu einer asymptomatischen Infektion. Zwischen den pantropen und den neurotropen Stämmen besteht eine Kreuzimmunität.

Durch fortlaufende Passagen eines pantropen Stammes des Gelbfiebervirus in Gewebekulturen wurde der relativ avirulente 17 D Stamm erhalten. Dieser Stamm hatte seine Fähigkeit, bei Affen und Menschen eine viscerotrope oder neutrotrope Erkrankung zu induzieren verloren und wird jetzt als Vakzine verwendet. Das in der Vakzine enthaltene Virus kann 10000 fach verdünnt werden und ruft bei den intracerebral hiermit inokulierten Mäusen immer noch eine tödlich endende Encephalitis hervor.

D. Antigenität: Aus infizierten Mäusehirnen oder aus der Leber oder auch aus dem Blut infizierter Affen kann ein komplementbindendes Antigen hergestellt werden. Das in diesem Test reagierende Antigen ist offenbar nicht das Virus selbst. Es kann sich vielmehr um ein Produkt der Einwirkung des Gelbfiebervirus auf das infizierte Gewebe handeln. Auf Grund der Kreuzreaktion bei der Komplementbindungsreaktion und bei dem Hämagglutinationshemmungstest läßt sich das Gelbfiebervirus als ein Mitglied der Gruppe B der durch Arthropoden übertragenen Viren einstufen.

\section{Pathogenese und Pathologie}

Unsere Kenntnisse über die Pathogenese des Gelbfiebers beruhen auf Untersuchungen über die experimentelle Infektion des Affen. Das Virus dringt durch die Haut ein und breitet sich dann bis zu den lokalen Lymphknoten aus, in denen es sich vermehrt. Von den Lymphknoten dringt es in die Blutbahn ein und setzt sich in Leber, Milz, Niere, Knochenmark und Lymphknoten fest. Auch wenn das Virus nicht mehr im Blut nachzuweisen ist, so kann es noch einige Tage lang in der Milz, im Knochenmark und in den Lymphknoten vorhanden sein. Nach Verabreichung hochvirulenter Stämme (Asibi) findet sich die höchste Viruskonzentration in der Leber. Nach Inokulation eines abgeschwächten Stammes (17 D) wird der Erreger lediglich in der Milz, in den Lymphknoten und dem Knochenmark gefunden.

Die beim Gelbfieber gefundenen pathologisch-anatomischen Läsionen sind die Folge der Haftung und Vermehrung des Virus in einem bestimmten Organ. Der Tod ist die Folge der schweren Nekrosen in der Leber und in den Nieren, die die deutlichsten Veränderungen zeigen. Bei schweren Erkrankungsfällen kann es zu einer fast vollständigen Zerstörung des Leberparenchyms kommen. Bei tödlich endenden Gelbfiebererkrankungen finden sich häufig Haemorrhagien in der Mukosa am Pylorus-nahen Teil des Magens.

Die nekrotischen Zellen sind in der Leber fleckförmig verteilt, die Nekrose ist hyalin und kann auf das Cytoplasma der Zellen beschränkt sein, obwohl im allgemeinen die ganze Zelle betroffen ist. Die irregulär geformten hyalinen Massen sind eosinophil und werden als Councilman-Körperchen bezeichnet. Außerdem kann man intranukleäre Einschlußkörperchen finden, die auch einigen diagnostischen Wert besitzen. Haemorrhagien sind in der Leber selten. In der Rekonvaleszenz werden die parenchymatösen Zellen erneuert und 
die Leberfunktion wird vollständig ohne irgendwelche Zeichen einer Beeinträchtigung wieder hergestellt.

Die Läsionen in den Nieren bei einer Infektion durch Gelbfiebervirus sind durch eine fettige Degeneration des Tubulusepithels charakterisiert. Ferner beobachtet man degenerative Veränderungen in der Milz, in den Lymphknoten und im Herzen. Intranukleäre, acidophile Einschlußkörper können auch in der Nerven- und Gliazellen des Gehirns vorhanden sein. Hier im Gehirn treten außerdem perivaskuläre Infiltrate mit mononukleären Zellen auf.

\section{Klinische Befunde}

Die Inkubationszeit beträgt 3-6 Tage. Die Erkrankung beginnt mit Fieber, Schüttelfrost, Kopfschmerzen und Rückenschmerzen; darauf folgt rasch Schwindelgefühl und Erbrechen. Wegen der Haemorrhagien aus der Mukosa des Magens kann das Erbrochene schwarz aussehen. Bei schweren Fällen findet man ferner eine Proteinurie. Häufig besteht eine Bradycardie und eine Hypotonie. Im Blutbild läßt sich eine Lymphopenie feststellen. Bei jenen Patienten, bei denen die Erkrankung bis zu einem schweren Stadium fortgeschritten ist (Erbrechen schwarzer Massen und Gelbsucht), ist die Letalität hoch. Auf der anderen Seite kann die Infektion aber auch so milde verlaufen, daß sie unbemerkt vorüber geht. Gleichgültig wie schwer das Krankheitsbild ablief, es entstehen keine Dauerschäden, die Patienten erliegen entweder der Erkrankung oder erholen sich vollständig.

\section{Laboratoriumsdiagnose}

A. Virusisolierung: Bis zum 5. Tag der Erkrankung kann das Virus aus dem Blut isoliert werden. Intracerebral mit dem Serum eines Verdachtfalles inokulierte Mäuse sterben an einer Encephalitis, falls in dem Untersuchungsmaterial Virus vorhanden war. Nachdem das Virus isoliert wurde, muß es durch einen Neutralisationstest mit spezifischen Antiseren identifiziert werden.

Bei der Erstisolierung von Menschen verhalten sich einige Virusstämme ,paradox“. Hierbei treten nach Verimpfung des unverdünnten Serums keine Krankheitssymptome bei den Mäusen auf, während das gleiche Serum in den Verdünnungen 1:10 oder 1: 100 eine Encephalitis bei den inokulierten Mäusen hervorrufen kann. Dieses ,,paradoxe“ Verhalten kann folgende Ursachen haben: 1. Im Serum sind Antikörper in geringer Konzentration vorhanden und das Virus liegt in einem neutralen Virus-Antikörper-Gemisch vor. Durch einfache Verdünnung kann dieser Virus-Antikörper-Komplex teilweise dissoziiert werden und damit wird das Virus reaktiviert. 2. Außer dem infektiösen Virus ist ein verhältnismäßig großer Anteil von inaktivem Virus in der Serumprobe vorhanden, das mit der Vermehrung des aktiven Virus interferiert, wenn diese Serumprobe nicht verdünnt wird. Aus diesen Gründen muß das Serum unverdïnnt in eine Gruppe und in verschiedenen Verdünnungen in weitere Gruppen von Mäusen inokuliert werden.

B. Serologie: Auch bei schweren und tödlich verlaufenden Fällen entstehen bereits frühzeitig neutralisierende Antikörper (um den 5. Tag). Bei den Patienten, die die Infektion überleben, bleiben die Antikörper im Serum lebenslänglich nachweisbar. Ein Neutralisationstest wird durch Mischen verschiedener Serumverdünnungen mit einer bestimmten Virusmenge durchgefïhrt, das Virus-Serum-Gemisch danach intracerebral in erwachsene Mäuse oder intraperitoneal in infantile Mäuse verimpft.

Komplementbindende Antikörper findet man nach milde verlaufenen Infektionen oder nach Impfungen mit dem abgeschwächten vermehrungsfähigen $17 \mathrm{D}$ Stamm im allgemeinen nicht. Bei schwer verlaufenen Infektionen kann man sie nach dem Auftreten der neu- 
tralisierenden Antikörper feststellen, ihre Titerhöhe fällt jedoch rascher ab als diese. Nach ein paar Monaten sind komplementbindende Antikörper nicht mehr nachweisbar.

Die serologische Reaktion auf eine Gelbfieberinfektion kann zwei verschiedene Formen zeigen. Bei einer Primärinfektion mit dem Gelbfiebervirus entstehen zuerst spezifische hämagglutinationshemmende Antikörper, denen Antikörper gegen die anderen Viren der B Gruppe rasch folgen. Die homologen hämagglutinationshemmenden Antikörpertiter sind jedoch stets höher als die heterologen. Der Zeitpunkt, an dem nach Beginn der Erkrankung bei einer Primärinfektion komplementbindende Antikörper nachweisbar werden, ist wechselnd. Komplementbindende Antikörper lassen sich während eines verhältnismäßig langen Zeitraums nachweisen und können auch dann noch im Titer ansteigen, wenn die hämagglutinationshemmenden Antikörper langsam verschwinden. Der Ausfall der Komplementbindungsreaktion ist bemerkenswert spezifisch. Ein Überlappen mit anderen Antigenen wird nur dann beobachtet, wenn die homologen komplementbindenden Antikörpertiter hoch sind. Die nach einer Primärinfektion gebildeten neutralisierenden Antikörper, wie sie durch den üblichen intracerebralen Test festgestellt werden, sind weitgehend spezifisch. Heterologe neutralisierende Antikörper werden nur in einem begrenzten Umfang gebildet.

Nach einer Zweitinfektion kommt es dagegen zu einer sehr raschen und deutlichen Bildung hämagglutinationshemmender und komplementbindender Antikörper. Eine Spezifität dieser Antikörper ist nicht einmal andeutungsweise vorhanden. Tatsächlich werden die höchsten Titer hämagglutinationshemmender und komplementbindender Antikörper gegen heterologe Viren erreicht. Außerdem wird bei Sekundärinfektionen die Bildung heterologer neutralisierender Antikörper in einem stärkeren Umfang angeregt als dies bei Primärinfektionen der Fall ist. Die heterologe Reaktion kann so ausgeprägt sein, daß es unmöglich wird, eine spezifische Diagnose durch den Neutralisationstest zu stellen.

Die histologische Untersuchung der Leber ist bei tödlich velaufenden Fällen in endemischen Gebieten wertvoll.

\section{Immunität}

Alle Stämme des Gelbfiebervirus gehören zu einem Antigentyp, einschließlich der aus ländlichen oder städtischen Gebieten in Südamerika oder Afrika isolierten Stämme. Die Frage, ob Gelbfieber in einigen Gegenden der Welt durch die hier endemische Dengue unterdrückt wird, muß offen bleiben (s. Seite 414).

Ein von einer immunen Mutter geborenes Kind besitzt bei der Geburt Antikörper, die während der ersten 6 Lebensmonate langsam verlorengehen. Der erneute Erwerb dieser Antikörper hängt von der individuellen Exposition gegenüber dem Virus unter den natïrlichen Bedingungen oder von einer Impfung ab.

\section{Epidemiologie}

Gelbfieber wird von Mensch zu Mensch durch die Mücke Aedes ägypti übertragen. Diese Mücke lebt in der Nähe menschlicher Wohnungen, wobei sie in Wasserlachen in der Nähe dieser menschlichen Siedlungen brütet. Die Mücke infiziert sich durch einen Biß bei einem infizierten Menschen, der sich im virämischen Stadium der Erkrankung befindet. Wo ein ständiger Zustrom empfänglicher Menschen besteht, wird der Infektionszyklus des Städtegelbfiebers durch einige Gelbfiebererkrankungen und Aedes ägypti aufrechterhalten. Durch intensive Maßnahmen zur Einschränkung der Mückenverbreitung ist das Städtegelbfieber in Südamerika praktisch ausgerottet. Es hat sich jedoch herausgestellt, daß bei Menschen in ländlichen Gebieten „Dschungel“-Gelbfieber auftreten kann, ferner auch bei solchen Menschen, die in Gebieten leben, in denen Aedes ägypti nicht vorkommt. 
Dschungelgelbfieber ist in erster Linie eine Erkrankung von Affen (und vielleicht noch von einigen anderen Waldtieren). Die Erkrankung wird von Affe zu Affe durch Mücken, die in diesen Wäldern leben, übertragen. Die Infektion bei den Tieren kann als schweres Krankheitsbild auftreten oder auch inapparent verlaufen. Kommen Personen, wie z.B. Holzfäller, Nüssesammler oder Straßenbauarbeiter in Kontakt mit diesen Mücken im Wald, so werden sie sekundär in diesen Infektionszyklus einbezogen. Dschungelgelbfieber kann außerdem auch dann auftreten, wenn ein infizierter Affe eine menschliche Ansiedlung aufsucht, durch Aedes ägypti gestochen wird, die dann wiederum das Virus auf den Menschen überträgt.

Verschiedene Moskitoarten und verschiedene Tiere in den einzelnen Gebieten der Welt übertragen das Dschungelgelbfieber. In Südamerika bilden bestimmte Affenarten sowie Mücken der Gruppe Haemagogus das Reservoir. In Afrika sind es wiederum einzelne Affenarten, wobei Aedes ägypti als Überträger dient.

Das Virus vermehrt sich in den Mücken, die lebenslänglich infektiös bleiben. Nachdem die Mücke virushaltiges Blut aufgesogen hat, ist ein Intervall von $12-14$ Tagen erforderlich bis die Tiere infektiös werden. Dieses Intervall nennt man die externe Inkubationszeit.

Die Trockenzeit überlebt das Virus in den Mücken, die in den Spitzen bestimmter Waldbäume, wo sich Wasser ansammelt, leben und brüten.

Alle Altersgruppen sind für eine Infektion empfänglich, aber die Erkrankung bei Kleinkindern soll milder verlaufen als bei älteren Menschen. Inapparente Infektionen sind häufig.

Obwohl einzelne schwerverlaufende Epidemien bei Negern beobachtet wurden, verläuft die Erkrankung im allgemeinen bei ihnen jedoch milder als bei den Menschen anderer Rasse. Über ein Vorkommen von Gelbfieber in Indien ist niemals etwas berichtet worden, obwohl der Überträger, Aedes ägypti, dort weit verbreitet ist.

\section{Kontrolle}

Energische Maßnahmen zur Eindämmung der Mückenverbreitung haben das Städtegelbfieber praktisch ausgerottet. Bei der Schnelligkeit des modernen Lufttransportes müssen die Gesundheitsbehörden in Gebieten, wo die Infektion sich nach ihrem Einschleppen festsetzen könnte, außerordentlich wachsam sein. Die meisten in Frage kommenden Länder bestehen auf einer ausreichenden Mückenkontrolle der Flugzeuge und der Impfung aller Personen mindestens 10 Tage vor der Ankunft in einem endemischen Gebiet oder der Abreise aus einem derartigen Endemiegebiet.

In dem 17 D Stamm steht eine ausgezeichnete abgeschwächte Lebendvakzine zur Verfügung. Die Vakzine wird in Eiern hergestellt und dann als Trockenpulver in kleinen Ampullen in den Handel gebracht. Da es sich um eine Lebendvakzine handelt, müssen diese Ampullen kalt gelagert werden. Unmittelbar vor Gebrauch rehydratisiert man den Inhalt der Ampulle und injiziert ihn subkutan. Die Vakzine enthält Hühnereiweiß und aus diesem Grund müssen die Impflinge vorher über eine mögliche allergische Reaktion gegen derartiges Eiweiß befragt werden. Ist eine derartige Reaktion zu erwarten, so muß der Impfling durch Injektion kleinster Dosen desensibilisiert werden. Die Vakzine kann man außerdem durch Skarifikation der Haut mit ebenfalls sehr guten Resultaten verabreichen. Eine einzige Injektion führt bei $90 \%$ der Geimpften zu einer guten Antikörperbildung, die etwa 2 Jahre anhält und bei etwa $70 \%$ zu einer Antikörperbildung, die 9 Jahre anhält. Menschen mit einem hohen Expositionsrisiko sollte man alle 3 Jahre revakzinieren. Nach der Impfung vermehrt sich das Virus und kann aus dem Blut isoliert werden, bevor sich Antikörper bilden. 


\section{Dengue}

Dengue ist eine durch Mücken übertragene Infektionskrankheit, die durch Fieber, Schmerzen und ein Exanthem gekennzeichnet ist.

\section{Eigenschaften des Virus}

A. Größe: Der Durchmesser des Virus beträgt nach Filtrationsergebnissen etwa 17 $25 \mathrm{~m} \mu$.

B. Verhalten gegenüber physikalischen und chemischen Einflüssen: Das Virus ist zumindest 5 Monate lang im gefrorenen Zustand bei $-70^{\circ} \mathrm{C}$ stabil und im lyophilisierten Zustand bei $+5^{\circ} \mathrm{C}$. Menschliches Blut kann infektiös bleiben, wenn es bei $5^{\circ} \mathrm{C}$ wochenlang aufbewahrt wird. Durch UV-Licht oder durch $0,05 \%$ Formalin kann das Virus inaktiviert werden. Dieses inaktivierte Virus ist nicht in der Lage, eine Immunität zu erzeugen.

C. Empfänglichkeit von Tieren: Menschliches Serum, das Denguevirus enthält, führt lediglich zu einer inapparenten Infektion bei Schimpansen und Affen. Nach der Infektion kommt es zum Auftreten komplementbindender und neutralisierender Antikörper, die mehrere Monate lang bestehen bleiben.

Verschiedene Virusstämme wurden an Mäuse adaptiert. Nach intracerebraler Inokulation zeigen die Mäuse schlaffe Lähmungen, wobei die histologischen Läsionen vorwiegend in den Neuronen zu suchen sind. Mäuse-adaptiertes Denguevirus kann eine tödlich verlaufende paralytische Erkrankung bei Affen hervorrufen, die sowohl im klinischen als auch im pathologisch-anatomischen Aspekt der experimentellen Poliomyelitis ähnlich ist.

Die Inokulation von Dengue-virushaltigem menschlichem Serum in Mäuse führt selten zur Ausbildung von Krankheitssymptomen. In den ersten Tagen nach der Injektion sind diese Tiere jedoch gegenüber dem mausadaptierten Virus resistent. Diese Tatsache beruht auf einer Interferenz; später werden die Mäuse als Folge einer aktiven Immunität dann resistent.

In Affennieren-, Hamisternieren- und HeLazellen vermehrt sich Denguevirus sehr gut, wobei es cytopathische Veränderungen verursacht, die zur Titration des Virus und zur Messung neutralisierender Antikörper verwendet werden können.

D. Antigenität: Aus den Hirnen infizierter saugender Mäuse können komplementbindende und hämagglutinierende Antigene hergestellt werden. In der menschlichen Milch hat man einen antiviralen Faktor gefunden, der die Vermehrung aller Viren der Dengue-Gelbfieber-Gruppe hemmt, jedoch nicht die Vermehrung anderer Viren. Obwohl Dengue und Gelbfiebervirus eine Gruppenverwandtschaft zeigen, findet sich zwischen ihnen keine Kreuzimmunität. Menschliche Freiwillige, die mit Gelbfiebervirus immunisiert worden waren. konnten durch kleine Dosen von Denguevirus noch infiziert werden. Es konnte jedoch eine Interferenz nachgewiesen werden, wenn Denguevirus bis zu 7 Tagen nach der Immunisierung mit abgeschwächten Gelbfiebervirus inokuliert wurde. Eine vorausgegangene Immunisierung gegen Gelbfieber führt ferner bei der späteren Infektion mit einem abgeschwächten Denguevirusstamm zu einer verbreiterten anamnestischen Reaktion gegenüber der Denguevakzine.

\section{Pathogenese und Pathologie}

Nach dem Eindringen des Virus durch den Biß einer Mücke entsteht ein lokales Ödem und Erythem $(10-40 \mathrm{~mm}$ im Durchmesser). Diese Läsion ist die Folge einer lokalen Virusvermehrung. Innerhalb von 24 Stunden nach dem ersten Fieberanstieg kann das Virus 
im Serum in hohem Titer nachgewiesen werden. Histologische Läsionen finden sich in und um die kleinen Blutgefäße, wobei sich eine Endothelschwellung, ein perivasculäres Ödem und eine Infiltration mit mononukleären Zellen bildet.

Die intradermale Inokulation kleiner Virusdosen kann entweder zu einer typischen Dengue-Erkrankung führen oder einer milden Erkrankung ohne Exanthem oder auch ohne Krankheitssymptome bleiben. Nach allen drei Fällen entsteht eine Immunität, obwohl diese nach inapparenter Infektion durch minimale infektiöse Dosen am wenigsten dauerhaft ist. Ein Laboratoriumsarbeiter erkrankte an Dengue 9 Tage nachdem Serum von einem Patienten ihm durch Zufall ins Auge gespritzt war.

\section{Klinische Befunde}

Die Inkubationszeit beträgt 5-8 Tage. Das Fieber kann entweder plötzlich einsetzen oder es können auch einige Prodromalsymptome in Form eines allgemeinen Krankheitsgefühls, Schüttelfrostes oder Kopfschmerzen vorhanden sein. Danach treten rasch Schmerzen auf, vor allem im Rücken, in den Gelenken, in den Muskeln und in den Augäpfeln. Häufig findet sich ein gerötetes Gesicht und injizierte Conjunctiven. Nach 5-6 Tagen kehrt die Temperatur wieder zur Norm zurück oder aber sie geht nach 3 Tagen etwas zurück und steigt etwa 5-8 Tage nach Beginn der Erkrankung erneut an (,Sattelform“). Am 3. oder 4. Tag entsteht ein maculo-papulöses oder auch ein scarlatiniformes Exanthem, das selten länger als 72 Stunden bestehen bleibt. Die Häufigkeit des Auftretens von Exanthemen ist von Epidemie zu Epidemie verschieden. Die Lymphknoten sind häufig vergrößert. Regelmäßig tritt eine Leukopenie mit einer relativen Lymphocytose auf.

Die Rekonvaleszenz kann Wochen dauern, obwohl Komplikationen oder Todesfälle selten sind. Bisher konnte Dengue niemals als eine primäre Todesursache festgestellt werden.

Dengue kann auch unter dem Bild einer milden, $1-3$ Tage dauernden fieberhaften Erkrankung auftreten. Dengue sollte immer dann vermutet werden, wenn ein Patient kurz nach Ankunft in einem Gebiet, in dem Mücken als Überträger in Frage kommen, erkrankt oder wenn ein Patient aus einem derartigen Gebiet einreist.

Ein haemorrhagisches Fieber, wie es auf den Philippinen und in Thailand auftritt, konnte kürzlich als Folge einer Infektion durch 2 neu entdeckte Typen des Denguevirus (Typ 3 und 4 ) festgestellt werden. Diese Typen 3 und 4 unterscheiden sich in ihrer Antigenstruktur von den klassischen Stämmen, die zu den Typen 1 und 2 gehören.

\section{Laboratoriumsdiagnose}

Obwohl es gelungen ist, das Virus an Mäusen zu adaptieren, kann dieses Vorgehen kaum als diagnostische Methode im Laboratorium angesehen werden, da die Isolierung eines Virus zu schwierig ist.

A. Verdachtsdiagnose: Bei dieser Untersuchung wird eine Gruppe von Mäusen mit frischem Serum aus der akuten Krankheitsphase inokuliert, eine andere Gruppe von Mäusen mit erhitztem Serum $\left(56^{\circ} \mathrm{C}, 30\right.$ Min. lang). Einen Monat später führt man bei beiden Gruppen von Mäusen eine Belastungsinokulation mit 100 LD 50 eines bekannten, an Mäuse adaptierten Denguevirusstammes durch. Überleben die Mäuse, die das frische Serum erhielten, diese Belastung, während jene Mäuse, denen das erhitzte Serum inokuliert wurde, sterben, so enthielt das Serum Denguevirus.

B. Serologie: Nach der Infektion bilden die Patienten neutralisierende und hämagglutinationshemmende Antikörper, die innerhalb von 7 Tagen nach Krankheitsbeginn nach- 
weisbar sind, während die komplementbindenden Antikörper etwa 7-14 Tage später entstehen.

Zur Feststellung von Antikörpern müssen sowohl die Antigene des Types 1 wie des Types 2 des Denguevirus verwendet werden. Der Patient bildet zwar sowohl homotype als auch heterotype Antikörper gegen Denguevirus, jedoch kann der infizierende Typ auf Grund folgender Unterschiede bei der Antikörperbildung ermittelt werden: 1. Neutralisierende Antikörper: homotype Antikörper weisen einen höheren Titer als heterotype auf. Zur Neutralisation eines Mäuse-adaptierten Virus ist zusätzlich zu dem hitzestabilen Antikörper $\left(56^{\circ} \mathrm{C}, 30\right.$ Min. lang) der Zusatz eines unspezifischen, Komplement-ähnlichen, hitzelabilen zusätzlichen Faktors erforderlich.

2. Komplementbindende Antikörper: Nur gelegentlich ist die Antikörperbildung gegen das homologe und das heterologe Antigen gleich, in den meisten Fällen sind die heterologen Antikörpertiter niedriger und sind weniger lange nachweisbar als die homologen.

3. Hämagglutinationshemmende Antikörper: Die homologen Antikörper können 1 Woche früher auftreten, einen höheren Titer besitzen und länger nachweisbar sein als die heterologen Antikörper. Ferner werden auch Antikörper gegen die anderen Mitglieder der Gruppe B der Arborviren gebildet.

\section{Immunität}

Man kennt zumindest 4 Antigentypen des Virus. Dies ergibt sich aus folgenen Befunden: 1. Aktive Kreuzimmunitätsuntersuchungen bei menschlichen Freiwilligen, 2. Hautneutralisationsteste mit Rekonvaleszentenserum bei menschlichen Freiwilligen, 3. Neutralisationstest in Mäusen mit Rekonvaleszentenseren von Patienten und von Affen und 4. Komplementbindungsreaktionen und Hämagglutinationshemmungsteste mit Seren von Patienten und Affen.

Die Reinfektion bei einem Menschen, der 2-3 Monate vorher durch einen anderen Typ des Denguevirus infiziert worden war, kann zu einem allgemeinen Krankheitsgefühl sowie einem kurzdauernden geringen Fieberanstieg führen. Läßt man an diesem reinfizierten Patienten Mücken saugen, so können diese die Erkrankung weiter übertragen. Versucht man eine heterotype Infektion zu einem späteren Zeitpunkt zu erzielen, so entsteht häufig eine fieberhafte Erkrankung von 2-3 Tagen Dauer ohne Exanthem. Derartige Bedingungen, die das Erkrankungsbild bei einer Zweitinfektion modifizieren können, bestehen vielleicht auch in der Natur, da zwei verschiedene Antigentypen des Denguevirus gleichzeitig in dem gleichen Gebiet isoliert werden konnten und da außerdem bei einzelnen Epidemien eine große Anzahl atypischer Fälle auftraten. Man kann annehmen, daß dieser Effekt auf einem gemeinsamen Antigen beruht und nicht auf unspezifische Resistenz zurückzuführen ist.

Durch die Adaptierung an Mäuse und an Gewebekulturen wurden die Stämme abgeschwächt; Stämme ohne paralytogene Fähigkeit für den Affen werden als Vakzine empfohlen. Nach Injektion eines abgeschwächten Virus besitzen Menschen eine belastbare Immunität gegenüber nicht-modifiziertem Virus, das durch infizierte Mücken oder auch durch die Inokulation großer Mengen hochinfektiösen menschlichen Serum übertragen wurde.

Früher gegen Gelbfieber Geimpfte zeigen eine breite anamnestische Antikörperbildung nach Immunisierung mit abgeschwächtem Denguevirus. Dasselbe trifft für die Menschen $\mathrm{zu}$, die früher durch andere Arborviren infiziert worden waren.

\section{Epidemiologie}

Die Erkrankung tritt in den Ländern des östlichen Mittelmeeres, in Afrika, Indien, dem fernen Osten, auf Hawaii und auf den Karibischen Inseln auf. Sie ist auch in den südlichen 
Staaten der USA und in Australien beobachtet worden. Denguevirus wird lediglich durch bestimmte Spezies von Aedes, vor allem durch Aedes ägypti übertragen. Der Infektionszyklus zeigt folgenden Verlauf:

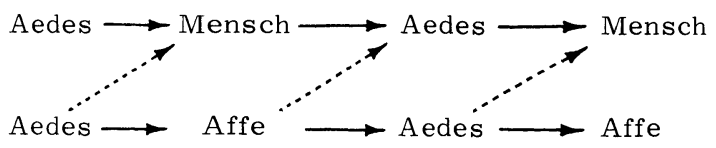

Aedes ägypti ist eine in der Nähe menschlicher Behausungen lebende Mückenart, Aedes albopictus lebt dagegen im Busch oder im Dschungel. Von dieser letzten Mückenart nimmt man an, daß sie die Infektion unter Affen (Dschungel-Dengue) aufrecht erhält. Bei Epidemien von Dengue werden im allgemeinen große Bevölkerungsteile innerhalb einer kurzen Zeit infiziert, was im Hinblick auf die große Zahl infizierter Tieren, die als Vektor dienen können, und einer großen Zahl empfänglicher Personen zu erwarten ist.

Saugen Mücken an infizierten Wirten in einem Zeitraum zwischen 12 Stunden vor und 72 Stunden nach dem Auftreten der Symptome, so werden diese Mücken infiziert. Eine externe Inkubationszeit von 11-14 l'agen ist erforderlich, bevor die Mücken das Virus übertragen können; sie können dann für den Rest ihres Lebens (1-3 Monate oder länger) als Vektor dienen. Lediglich 1-2 der Insekten sind erforderlich, um die Infektion zu uibertragen.

Anhaltspunkte für eine Übertragung des Virus von einer Generation der Mücke auf die nächste gibt es nicht. Die Erkrankung tritt hauptsächlich in tropischen Gebieten auf, wo die Mücken während des ganzen Jahres vorhanden sind. Ausbrüche in kälteren Gebieten werden im allgemeinen durch den Beginn der kalten Jahreszeit beendet.

Häufig kann man Epidemien von Dengue beobachten, wenn das Virus in neue Gebiete eingeschleppt wird, oder wenn empfängliche Menschen - wie z. B. Militär - in endemische Gebiete hineinkommen. Wenn der Viruszyklus das ganze Jahr über aufrecht erhalten wird, so kann die Krankheit endemisch werden, wie es im Gebiet der Karibischen See geschehen ist. Wird die Infektion dagegen in ein Gebiet mit gemäßigtem Klima eingeschleppt, wo der Vektor während des Winters verschwindet, so kommt die Epidemie dann sofort zu einem Stillstand und tritt im nächsten Jahr nicht erneut auf. Aus diesem Grund ist die endemische Dengue auf den Inseln der Karibischen See im Hinblick auf die Mücke Aedes ägypti, die in den Sommermonaten allgemein verbreitet ist, eine ständige Bedrohung für die USA. 1934 trat eine große Epidemie von Dengue, während der viele Tausend Personen erkrankten, im südlichen USA auf. Die Epidemie kam mit dem Einbruch des Winters zum Stillstand.

\section{Kontrolle}

Die Kontrolle der Erkrankung hängt entscheidend von den Maßnahmen der Mückenbekämpfung ab, d.h. Vernichtung der Brutplätze und Verwendung von Insektiziden, z. B. DDT. Für experimentelle Zwecke wurde eine abgeschwächte Virusvakzine hergestellt, die jedoch noch nicht in einem großen Feldversuch erprobt wurde.

\section{Pappatacifieber}

(Phlebotomusfieber)

Pappatacifieber ist eine milde verlaufende, durch Insekten übertragene Erkrankung, die vor allem in den Mittelmeerländern und in Rußland, China und Indien auftritt. In den endemischen Gebieten zwischen dem 20. und 45. Breitengrad findet sich die Sandfliege, Phlebotomus papatasii. 


\section{Eigenschaften des Virus}

Das Virus hat einen Durchmesser von etwa $25 \mathrm{~m} \mu$. Man kennt mindestens 2 verschiedene Antigentypen. Der Erreger ist in seiner Antigenität von der Dengue - Encephalitis Gelbfieber - Gruppe unterscheidbar. Das Virus kann in Gewebekulturen vermehrt werden und ist auch an saugende Hamster und Mäuse adaptiert worden, bei denen sich eine Encephalitis zeigt. Einige Stämme sind auch pathogen für erwachsene Mäuse. Gegenüber Einfrieren und Lyophilisieren erweist sich der Erreger als stabil.

\section{Klinische Befunde}

Beim Menschen führt der Biß der Sandfliege zu einer kleinen, juckenden Papel, die bis zu 5 Tagen bestehen bleiben kann. Wenn das Virus durch den Biß der Sandfliege eindringt, beginnt die Erkrankung abrupt nach einer Inkubationszeit von 3-6 Tagen. In einem Zeitraum von 24 Stunden vor und 24 Stunden nach dem Beginn des Fiebers kann das Virus aus dem Blut isoliert werden. Die Symptome bestehen in Kopfschmerzen, einem allgemeinen Krankheitsgefühl, Schwindel, Fieber, conjunctivaler Injektion, einer Photophobie, Nackensteife, Leibschmerzen und einer Leukopenie. Alle Patienten erholen sich nach dieser Infektion vollständig. Eine spezifische Behandlung ist nicht bekannt. Die beim Menschen auftretenden pathologisch-anatomischen Veränderungen sind ebenfalls unbekannt.

\section{Laboratoriumsdiagnose}

Die Diagnose wird im allgemeinen nach dem klinischen Bild gestellt. Sie kann durch den Nachweis eines Antikörperanstieges bei Untersuchung mehrerer Serumproben bestätigt werden, wobei man entweder einen Neutralisationstest mit einem Mäuse-adaptierten Virus durchführt oder einen Hämagglutionationshemmungstest, bei dem ein Hämagglutinin benutzt wird, das mit dem Virus gekoppelt ist.

\section{Immunität}

Die Immunität ist spezifisch für jeden Antigentyp des Virus und bleibt mindestens 2 Jahre lang bestehen. Während der Mäusepassagen kann das Virus abgeschwächt werden und könnte unter Umständen als Lebendvakzine verwendet werden, jedoch sind solche Versuche bisher nicht unternommen worden.

\section{Epidemiologie}

Die Erkrankung wird durch die weibliche Phlebotomus-Mücke, die nur wenige Millimeter groß ist, übertragen. Die Sandfliege ist in den Tropen das ganze Jahr über verbreitet; in Gebieten mit einem kühleren Klima findet man sie nur während der warmen Jahreszeit. Es ist nicht genau bekannt, wie das Virus überwintert.

Die externe Inkubationszeit in der Sandfliege beträgt etwa 1 Woche. Das Insekt saugt während der Nacht, während des Tages kann man die Sandfliege an dunklen Plätzen (Mauerrisse, Höhlen, Häuser, Baumstämme) finden. Wenige Tage nach dem Blutsaugen werden die Eier abgelegt, bis zur Entwicklung fertiger Insekten sind etwa 5 Wochen erforderlich. Bei heißem Wetter leben die erwachsenen Tiere nur wenige Wochen.

In endemischen Gebieten tritt die Infektion und damit auch die Immunität häufig bereits während der Kindheit auf. Kommen empfängliche Erwachsene (z.B. Militär) in diese Gebiete, so können größere Ausbrüche von Pappatacifieber unter den Neuankömmlingen auftreten, wobei diese Erkrankung dann gelegentlich als Malaria mißdeutet wird.

\section{Kontrolle}

Sandfliegen sind unmittelbar oberhalb des Bodens am meisten verbreitet. Da es sich um sehr kleine Tiere handelt, können sie durch die üblichen Fliegenfenster und Moskito- 
netze hindurchtreten. Ihre Flugstrecke kann fast 200 Meter betragen. Zur Vorbeugung von Erkrankungen in endemischen Gebieten ist eine Insektenabwehr in der Nacht unter Verwendung von Insektiziden in und um die Quartiere erforderlich.

\section{Colorado-Zeckenfieber}

(Bergfieber, Zeckenfieber).

Colorado-Zeckenfieber ist eine milde verlaufende, fieberhafte Erkrankung ohne Exanthem, die durch Zecken übertragen wird.

\section{Eigenschaften des Virus}

Nach Filtrationsversuchen beträgt der Durchmesser des Virus etwa 35-50 m $\mu$. Gegenüber Einfrieren und Lyophilisieren ist das Virus resistent. Eine thermische Inaktivierung des Erregers tritt nach einer 30 Min. dauernden Erhitzung bei $60^{\circ} \mathrm{C}$ ein. Das Virus ist pathogen für Hamster und Mäuse; nach intracerebraler Inokulation erkranken Mäuse mit Paresen. Der Erreger vermehrt sich ferner in Gewebekulturen menschlicher Zellen und im Hühnerembryo nach Inokulation in den Dottersack. Die höchste Viruskonzentration findet man im Zentralnervensystem des Embryos. Auf Grund seiner Antigenstruktur ist der Erreger des Colorado-Zeckenfiebers von allen anderen Erregern einschließlich der Dengueviren, der durch Zecken übertragenen Encephalitisviren und der durch Arthropoden übertragenen Rickettsien verschieden.

Pathogenese und Pathologie

Das Virus wird durch den $\mathrm{Bi} ß$ einer infizierten Zecke übertragen. Im akuten Stadium der Erkrankung kann man das Virus aus dem Blut isolieren. Die beim Menschen auftretenden pathologisch-anatomischen Veränderungen sind unbekannt.

\section{Klinische Befunde}

Die Inkubationszeit beträgt 4-6 Tage. Die Erkrankung beginnt akut mit Schüttelfrost und Schmerzen. Zu den typischen Symptomen gehören Kopfschmerzen, Augenschmerzen, Rückenschmerzen, Schwindel und Erbrechen. Der Temperaturverlauf ist im allgemeinen biphasisch. Nach dem ersten Abschnitt, der etwa 2 Tage dauert, kann eine relativ symptomarme Periode auftreten, bei der lediglich etwas Müdigkeit vorhanden zu sein pflegt. Die Symptome und das Fieber erscheinen dann im allgemeinen wieder und klingen nach 3-4 weiteren Krankheitstagen ab. Die Leukocyten gehen bei der Erkrankung bis auf 2-3000/ $\mathrm{cmm}$ herunter. Komplikationen sind unbekannt, über tödlich endende Erkrankungen wurde nicht berichtet.

\section{Laboratoriumsdiagnose}

Das Virus kann aus dem Blut durch intraperitoneale Inokulation infantiler Mäuse isoliert werden. Die Virämie bei Menschen dauert zumindest 2 Wochen. Experimentell infizierte Affen zeigen keinerlei Krankheitssymptome, aber es läßt sich bei ihnen eine zumindest 50 Tage lang anhaltende Virämie nachweisen.

Aus den infizierten Mäusehirnen kann ein spezifisches komplementbindendes Antigen gewonnen werden. Komplementbindende und neutralisierende Antikörper werden in der 2. Krankheitswoche gebildet und sind dann mindestens 3 Jahre lang nachweisbar. Die Weil-Felix-Reaktion ist negativ. 


\section{Immunität}

Man kennt nur einen Antigentyp. Eine einzige Infektion ist offenbar in der Lage, eine langhaltende Immunität zu erzeugen. Eine Lebendvakzine, die durch Adaptierung der Erreger an Hühnerembryonen gewonnen wurde, führt beim Menschen zu einer milde verlaufenden Erkrankung (druckempfindliche Lymphknoten, geringes Fieber), die in ihren Symptomen entfernt an das Colorado-Zeckenfieber erinnert. Die Impfung führt zur Bildung bleibender Antikörper und induziert eine Immunität gegen frisch von menschlichen Krankheitsfällen isolierte Stämmen.

\section{Epidemiologie}

Colorado-Zeckenfieber tritt nur in den Gebieten auf, in denen die Waldzecke, Dermacentor andersoni, vorkommt, z.B. Colorado, Oregon, Utah, Idaho, Montana und Wyoming. Nach Ausbruch einer Erkrankung läßt sich im allgemeinen retrospektiv feststellen, daß die Patienten 4-5 Tage vor Beginn der Symptome sich in einem mit Zecken befallenen Gebiet aufgehalten haben und in vielen Fällen findet man noch einzelne Zecken zu diesem Zeitpunkt an ihrem Körper. Die Erkrankung tritt vor allem bei erwachsenen Männern auf, da sie ein höheres Expositionsrisiko gegenüber den Zecken besitzen. In der Natur gesammelte Zecken (Dermacentor andersoni) waren mit dem Virus infiziert. Diese Zecke ist ein echtes Reservoir des Erregers, da das Virus transovariell durch das erwachsene Weibchen übertragen wird. Außerdem konnte das Virus von Hundezecken (Dermacentor variabilis), die auf Long Island gesammelt worden waren, isoliert werden, obwohl keine menschlichen Fälle in diesem Gebiet aufgetreten waren. Natürliche Infektionen treten bei Nagetieren auf, die als Wirte für die unreifen Entwicklungsstadien der Zecke in Betracht kommen.

\section{Kontrolle}

Die Erkrankung läßt sich am sichersten dadurch verhindern, daß man das Betreten durch Zecken befallener Wälder vermeidet. Falls dies nicht möglich ist, wird eine entsprechende Kleidung empfohlen (hohe Stiefel usw.), so daß die Zecken nicht ohne weiteres beißen könne.n. In Gebieten mitZeckenbefall sollte man Menschen regelmäßig auf etwa haftende Zecken ansehen und diese dann sobald wie möglich entfernen. Aus Hühnerembryonen, die mit Passagevirus infiziert worden waren, hat man eine abgeschwächte Lebendvakzine entwickelt und diese in begrenzten Versuchen erprobt. 